\title{
Three Sources of Increasing Returns to Scale
}

\author{
Jinill Kim* \\ First draft: March 1996 \\ This draft: April 3, 1997
}

\begin{abstract}
This paper reviews various types of increasing returns from a critical perspective. Increasing returns have been introduced both at the firm level and at the aggregate level in a monopolistic-competition model. We show that the degree of the aggregate returns to scale is a linear combination of three return parameters, with the weights determined by the specification of a zeroprofit condition. Identification issues are discussed with an emphasis on recent macro literature. We argue that disaggregate data give information on the market structure rather than the technology. Welfare implications explain why it is important to identify various increasing returns.
\end{abstract}

Key words: Increasing Returns; Monopolistic Competition; Returns to Variety JEL classification: E32

*Federal Reserve Board, Mail Stop 61, Washington, D.C. 20551. Telephone: (202) 452-2715. E-mail: jkim@frb.gov. This is a revised version of a chapter in my dissertation at Yale University. Special thanks to Christopher Sims for his guidance and support. Thanks also to William Brainard, John Fernald, Robert Shiller, Steve Sumner, Michael Woodford, and seminar participants at the Universities of Maryland and Virginia, and Federal Reserve Board for their valuable comments. This paper represents the view of the author and should not be interpreted as reflecting the views of the Board of Governors of the Federal Reserve System or other members of its staff. 


\section{Contents}

1 Introduction 2

2 The Model $\quad 4$

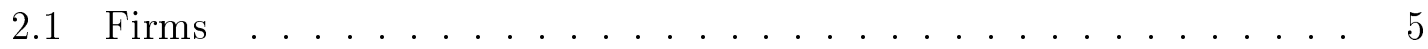

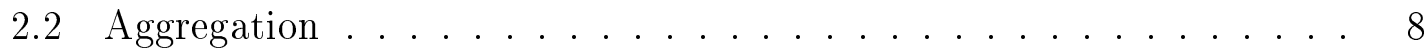

2.3 Returns to Scale . . . . . . . . . . . . . . 10

2.4 A Dynamic Model . . . . . . . . . . . . . . 15

3 Implications $\quad 19$

3.1 Identification with Aggregate Data . . . . . . . . . . . . 19

3.2 Interpretation of Disaggregate Data . . . . . . . . . . . . 21

3.3 Comparison with a Social Planner ............. 24

4 Further research $\quad 26$

A External Increasing Returns $\quad 28$

B Input Fixed Cost $\quad 29$

$\begin{array}{ll}\text { C Cost Minimization } & 31\end{array}$

D Fixed Cost Externalities 33

\section{Introduction}

The hypothesis of noncompetitive markets and/or increasing returns to scale has recently been used in dynamic stochastic general-equilibrium (DSGE), more often called real-business-cycle, models. Using the Solow residual as a measure of productivity changes is appropriate only under the joint hypothesis of perfectly competitive markets and constant returns to scale. In a series of papers, Hall (1986, 1988, 1990) argues that evidence from the Solow residual is not consistent with this maintained hypothesis but with the alternative hypothesis of noncompetitive markets and/or increasing returns to scale. ${ }^{1}$ Under this alternative hypothesis, the Solow residual has

\footnotetext{
${ }^{1}$ Imperfect competition makes equilibrium possible in the presence of increasing returns. Increasing returns are compatible with competitive firms if the increasing returns are external to the firms. Internal returns may be motivated as a representation of external ones, as in Beaudry and Devereux (1995a). The two types are compared using models with both types of increasing returns in Appendix A.
} 
endogenous components which cause it to over-represent the contribution of productivity shocks. Furthermore, this alternative hypothesis helps explain some puzzles in the DSGE literature, e.g. little correlation between employment and productivity.

Following Dixit and Stiglitz (1977) and Blanchard and Kiyotaki (1987), the monopolistic-competition framework has been widely used in macroeconomics. The assumption of unrestricted entry and exit implies that profits are zero in equilibrium. $^{2}$ In a monopolistically competitive market, the technology of constant returns to scale lets firms produce positive profits regardless of their size. Introducing increasing returns at the firm level leaves room for reducing profits to zero. ${ }^{3}$ The objective of this paper is to discuss three different types of increasing returns in a monopolistic-competition model and to derive implications for the related literature.

There are two ways of introducing increasing returns at the firm level. The more conventional way is including fixed costs as part of a firm's technology. This way has been followed whenever a zero-profit condition is imposed. An alternate way is amplifying the constant-returns-to-scale term by a power larger than one, which amounts to diminishing marginal cost. When we incorporate both sources of increasing returns simultaneously, as in Hornstein (1993), their effect on the aggregate returns to scale is different from each other. Increasing returns due to the third source occurs only at the aggregate level. It involves a technology or a preference for the variety of goods. The introduction of a new good might enhance the production efficiency and the consumption convenience. Romer (1987) focuses on this as an engine of growth and Matsuyama (1995) relates this to complementarities and cumulative processes of macroeconomics. The model in Devereux, Head and Lapham (1996a), even without productivity shocks, generates business cycle fluctuations of real variables from government spending shocks since these affect the variety of goods.

This paper shows that, in a static model, the resulting degree of aggregate returns to scale is the average of the second and the third sources of increasing returns, without any influence of positive fixed costs. The derivation of aggregate returns from a firm's technology involves two steps. First, the differentiated outputs are aggregated to produce a measure of aggregate output. Second, a zero-profit con-

\footnotetext{
${ }^{2}$ See Benassy (1991) for qualifications of zero-profit conditions. The assumption of zero profits matches the observation in Hall (1990) and Rotemberg and Woodford (1995) that there are no significant pure profits in the United States.

${ }^{3}$ Not that all papers in DSGE literature impose a zero-profit condition. Hairault and Portier (1993) and Beaudry and Devereux (1995b) do not impose a zero-profit condition and so parameterize both fixed cost and the number of firms. In such models, the firm-level returns to scale are the aggregate returns to scale and the permanent presence of positive profits remain unexplained. For example, the steady-state profit rate is $17 \%$ in the benchmark model of Hairault and Portier (1993).
} 
dition is imposed upon the aggregate version of a firm's technology. Specification of a zero-profit condition determines the weights of the averaging. In a dynamic model where adjustments to zero profit are not instantaneous, the market structure of monopolistic competition plays a role - the slower the adjustments, the larger the role. Even if market structure does not directly affect the technology, this source influences the response of output in a way indistinguishable from the previous two ways.

The aggregate dynamics of a model which combines various sources of increasing returns to scale show that there are identification problems in the recent macroeconomics literature using the framework of monopolistic competition. We compare various papers to see how they specify a zero-profit condition and what the resulting degree of returns to scale is. We also argue that the literature using disaggregate data provides information different from what it intends to provide: on the market structure rather the technology. Lastly, welfare implications are discussed from the perspective of a social planner who does not need to satisfy zero-profit conditions. While having similar positive implications for the aggregate returns, various increasing returns have different normative implications.

\section{The Model}

To illustrate the points in as simple a structure as possible, we analyze only the production side of the economy. This analysis is tractable and gives much insight on how different returns to scale interact with one another. Most papers on monopolistic competition deal with both the production and the consumption side of an economy. However, introducing a utility function complicates the model so that it is difficult to disentangle the production features from consumer behavior. Our model is a partial-equilibrium model, since the production side generates the demand for inputs. The transformation of this model into a general-equilibrium framework is straightforward by stacking it with a consumer problem and, if needed, a government problem. The consumer problem would generate the supply function of aggregate inputs through a labor-leisure choice and capital accumulation. Therefore, throughout this paper, we may consider the aggregate inputs as exogenous variables.

Since a zero-profit condition is crucial in deriving the economy-wide returns to scale, we will be very careful in discriminating two meanings of 'production function.' A structural production function is a purely technological relation without reference to the equilibrium condition of zero profits. However, a production function in a reduced form, whether a firm's or an aggregate one, is a combination of the appropriate technology and a zero-profit condition. That is, a reduced-form 
production function is a structural production function with a zero-profit condition imposed.

Now our objective of this section is to transform a firm-level structural production function, Eq. (1), into an aggregate reduced-form production function, e.g. Eqs. (16) and (24). This transformation is a contribution to the literature since it simplifies one step of complex DSGE models and so makes it easy to understand their production features. We start with a static model since it is a special case of a dynamic model. The static model serves as a steady-state, or low-frequency in general, feature of the dynamic model. As a preparation for the analysis of the aggregate variables, we analyze the behavior of firms.

\subsection{Firms}

Firms are identical except for the heterogeneity of outputs. Firm $i$ produces $y_{i}$ units of net output under a technology of increasing returns to scale:

$$
y_{i}=A_{i}\left(k_{i}^{\alpha_{i}} l_{i}^{1-\alpha_{i}}\right)^{\gamma_{i}}-\phi_{i}
$$

with the restrictions that $0 \leq \alpha_{i} \leq 1, \gamma_{i}>0$, and $\phi_{i}>0$. $A_{i}$ denotes the productivity shock, $k_{i}$ is the capital stock and $l_{i}$ is the quantity of labor. Since productivity shocks are not crucial in deriving the implications on returns to scale, they are normalized to 1 except when necessary for discussing econometric issues.

The parameter $\phi_{i}$ represents what firm $i$ should pay at each period regardless of its activity level. For example, a firm advertises its good each period to maintain its market share. Note that the fixed cost is measured in units of its own output, not its inputs. ${ }^{4}$ Additionally, this paper follows the convention that a firm's fixed cost is exogenous to the firm. The presence of a fixed cost makes it possible to impose a zero-profit condition, as in Hornstein (1993), Rotemberg and Woodford (1995), Beaudry and Devereux (1995a), and Devereux, Head and Lapham (1996a,b), and is a source of increasing returns to a firm's technology. However, in a static model, firm-level increasing returns due to fixed costs are not transmitted to the increasing returns of an aggregate production function in a reduced form, Eq. (16).

If $\gamma_{i}$ is greater than 1, a firm's gross output features additional increasing returns to scale. This source of increasing returns has not been popular in the literature. Actually, most papers in the DSGE literature restrict $\gamma_{i}$ to be exactly equal to 1 , except for Hornstein (1993) and Benhabib and Farmer (1994). This paper names

\footnotetext{
${ }^{4}$ Chatterjee and Cooper (1993) and Yun (1996) assume that fixed costs are a part of inputs. The models with input fixed costs behave in a similar way. See Appendix B for a model with fixed costs as part of its inputs.
} 
this source 'diminishing marginal cost.' Appendix $\mathrm{C}$ on cost minimization shows that the bigger $\gamma_{i}$ is, the smaller the slope of marginal cost is. Hornstein (1993) call this 'the scale coefficient.' However, we will show that the degree of returns to scale depends also on other parameters. Furthermore, diminishing marginal cost may not affect the response of aggregate output, depending on the specification of a zero-profit condition.

These two sources of increasing returns to scale at the firm level are added up in overall returns to scale of a firm's technology. From the perspective of a firm, to whom the fixed cost is exogenous, the log-linearized reduced-form production function is:

$$
y_{i} \simeq\left(k_{i}^{\alpha_{i}} l_{i}^{1-\alpha_{i}}\right)^{\left[\gamma_{i} \frac{y_{i}+\phi_{i}}{y_{i}}\right]} .
$$

That is, the degree of returns perceived by a firm is the product of the degree of diminishing marginal cost and the ratio between the gross and the net output. The ratio turns out to be $\left(\frac{\mu}{\gamma_{i}}\right)$, where $\mu$ is the degree of market power. This degree is assumed to be greater than $\gamma_{i}$ and defined in Eqs. (5) and (6). So the degree of returns to scale of a firm's technology is equal to the degree of market power. However, this exercise is meaningless in that we have not incorporated a zero-profit condition into a firm's technology. Actually, we will see that the presence of fixed costs by itself does not imply increasing returns in a static model. However, the degree of market power turns out be the right measure in a dynamic case where there are only steady-state adjustments to zero profit, without any period-by-period adjustments.

A firm maximizes its profit: ${ }^{5}$

$$
\pi_{i}=p_{i} y_{i}-P Z k_{i}-P W l_{i}
$$

where $p_{i}$ is the price of firm $i$ 's product, $P$ is the general price level, $Z$ is the real rental rate of capital, and $W$ is the real wage. In models with monopolistic competition, the price of outputs, $p_{i}$, depends on the amount produced, $y_{i}$. The inverse demand for the output of the $i$ th firm will be derived later in Eq. (8), which involves the parameter representing the market structure of monopolistic competition, $\mu$. The assumption that firms rent capital rather than holding and accumulating it simplifies the analysis. Under this assumption, we do not need to explain where entering firms buy capital or where exiting firms sell remaining

\footnotetext{
${ }^{5}$ An alternative, and probably more conventional way of analyzing the firm behavior is the framework of cost minimization in Appendix C. However, the profit-maximization framework is better for understanding the mechanics of the zero-profit condition since it expresses the endogenous variables as a function of aggregate inputs, considered exogenous in this paper. Furthermore, extension to a dynamic model becomes more complicated in the framework of cost minimization.
} 
capital. Capital and labor are homogeneous and a firm behaves as a price-taker in the input markets.

Noting that $y_{i}$ is a function of $\left(k_{i}, l_{i}\right)$, the first order conditions with respect to $k_{i}$ and $l_{i}$ are: ${ }^{6}$

$$
\begin{aligned}
\gamma_{i} \alpha_{i}\left(\frac{y_{i}+\phi_{i}}{k_{i}}\right)\left(\frac{p_{i}}{\mu}\right) & =P Z, \\
\gamma_{i}\left(1-\alpha_{i}\right)\left(\frac{y_{i}+\phi_{i}}{l_{i}}\right)\left(\frac{p_{i}}{\mu}\right) & =P W .
\end{aligned}
$$

Input prices determine the ratio between gross output — not net output - and each input. This point will be important later in comparing the dynamics of output with those of input prices. The first order conditions, Eqs. (2) and (3), determine the optimal capital and labor, depending on the demand curve and the size of the fixed cost. ${ }^{7}$ A firm's maximized profit is:

$$
\pi_{i}^{*}=p_{i}\left[\left(1-\frac{\gamma_{i}}{\mu}\right)\left(k_{i}^{\alpha_{i}} l_{i}^{1-\alpha_{i}}\right)^{\gamma_{i}}-\phi_{i}\right] .
$$

This derivation shows that neither form of increasing returns to scale is allowed in a perfectly competitive economy, i.e. when $\mu=1$. Introducing increasing returns would generate corner solutions. Therefore, the discussion of increasing returns in a competitive economy in Hall (1988) is futile. ${ }^{8}$ It is also interesting to note that marginal costs decreasing at a faster rate do not always benefit firms. Other things being equal, a firm would produce more output, which would decrease its profit by lowering its output price. If $\left(k_{i}^{\alpha_{i}} l_{i}^{1-\alpha_{i}}\right)$ is below a certain level, a faster rate means lower profits. Otherwise, profits become higher as $\gamma_{i}$ increases only when $\gamma_{i}$ is close to 1.

The zero-profit condition which should hold in equilibrium implies the following restriction:

$$
\phi_{i}=\left(1-\frac{\gamma_{i}}{\mu}\right)\left(k_{i}^{\alpha_{i}} l_{i}^{1-\alpha_{i}}\right)^{\gamma_{i}}
$$

The assumption of positive fixed costs is equivalent to the assumption that the degree of diminishing marginal cost $\left(\gamma_{i}\right)$ may not be larger than the degree of market

\footnotetext{
${ }^{6}$ Here we neglect the price-index effect of individual pricing decisions. See d'Aspremont, Ferreira and Gerard-Varet (1996) for this issue.

${ }^{7}$ If marginal cost is decreasing, the solution to (2) and (3) might not be a profit-maximizing choice. The restriction that $\phi_{i}$ is nonnegative is sufficient to guarantee that the choice defined by (2) and (3) maximizes profits in equilibrium.

${ }^{8}$ This is corrected in Hall (1990), where firms have market power under increasing returns.
} 
power $(\mu)$. This equation may be interpreted as determining the size of the fixed cost. However, it may also be interpreted as a condition deciding the number of firms, since $k_{i}$ and $l_{i}$ depend on the number of firms. Since aggregate inputs are considered exogenous in this paper, we should transform the zero-profit condition into a relation among aggregate variables. Before discussing aggregate implications of two firm-level increasing returns, we need to specify how the economy values the variety of goods in aggregation, which introduces the third source of increasing returns.

\subsection{Aggregation}

From a macroeconomic viewpoint, heterogeneous outputs need to be aggregated. A convention is introducing an additional agent in the economy, called an aggregator. The aggregator is equivalent to a firm producing a final good. The presence of the aggregator can be avoided, when every agent chooses the goods and labor index composition optimally, as in Blanchard and Kiyotaki (1987) and Hairault and Portier (1993). In this case, aggregation is a matter of preference as well as technology. Since this choice is static and the same for all agents, notation is simplified when the aggregator solves the problem instead.

The aggregator purchases differentiated outputs from firms, which are described by an $N$-dimensional vector, $\left(y_{1}, y_{2}, \ldots, y_{N}\right)$, and transforms them into $Y$ units of a final good. In the literature on monopolistic competition, the aggregating function follows both constant returns to scale and constant elasticity of substitution. The specification used by Dixit and Stiglitz (1977), and thenceforth conventional, is:

$$
Y=\left(\sum_{i=1}^{N} y_{i}^{\frac{1}{\mu}}\right)^{\mu}
$$

with $\mu>1$. The elasticity of substitution between two differentiated outputs is constant at $\frac{\mu}{\mu-1}$. Since $\mu$ is the markup in equilibrium, it is defined as the degree of market power. Besides determining the elasticity of substitution, the parameter plays an additional role involving the variety of goods.

If all goods are hired in the same quantity, $y$, then aggregate output is:

$$
Y=N^{\mu} y
$$

Thus, there are increasing returns to variety $(N)$, together with constant returns to quantity $(y)$. If the number of firms is constant in the model, this type of increasing returns does not produce aggregate increasing returns. Hornstein (1993) and Beaudry and Devereux (1995a) fall into this category. However, in a model 
where the number of firms is endogenous, increasing returns to variety do generate aggregate increasing returns, as in Devereux, Head and Lapham (1996a,b). They argue that increasing returns to variety capture the spirit of a thick-market effect and also explain the procyclical behavior of job creation and the entry of new firms. ${ }^{9}$

In the conventional specification of Eq. (5), the degree of increasing returns to variety is linked to the degree of market power. Theoretically speaking, there is no a-priori reason to prefer the presence or the absence of increasing returns to variety. Furthermore, with all the agreement on the presence of increasing returns to variety, the degree does not need to be related to the degree of market power, as in Eq. (5). This paper parameterizes, and so disentangles, the degree of returns to variety separately from that of market power. Dixit and Stiglitz (1975) - a workingpaper version of Dixit and Stiglitz (1977) - and Benassy (1996) also disentangle the two parameters, but this is not related to the degree of returns to scale.

Disentangling the two parameters is not just a theoretical curiosity. We will show that input prices, as a function of aggregate variables in Eqs. (26) and (27), are a function of the variety parameter but not of the market structure parameter. Therefore, only the former contributes to the existence of equilibrium indeterminacy. Besides, comparing the economy of monopolistic competition with that of a social planner, we will show that the two parameters have different welfare implications. These two points will be discussed after the algebra of the model.

This paper parameterizes the aggregator as follows: ${ }^{10}$

$$
Y=N^{\rho-\mu}\left(\sum_{i=1}^{N} y_{i}^{\frac{1}{\mu}}\right)^{\mu},
$$

which results in the following equation for aggregate output at symmetry:

$$
Y=N^{\rho} y
$$

The new parameter, $\rho$, represents the returns to variety. If it is greater than 1 , there are increasing returns to variety. Note that Eq. (5) corresponds to the case when $\rho$ is equal to $\mu$. If it is equal to 1 , the aggregator implies constant returns to variety

\footnotetext{
${ }^{9}$ Romer (1987) and Devereux, Head and Lapham (1996a,b) call this a return to 'specialization' rather than 'variety.' Following the title of Dixit and Stiglitz (1977), Chatterjee and Cooper (1993) use the terminology of 'product diversity.'

${ }^{10} \mathrm{~A}$ new multiplicative term, $N^{\rho-\mu}$, is called the "public-good feature of diversity" in Dixit and Stiglitz (1975). Two equivalent representations are $\left(\sum_{i=1}^{N} N^{\left(\frac{\rho}{\mu}-1\right)} y_{i}^{\frac{1}{\mu}}\right)^{\mu}$ and $\left(\sum_{i=1}^{N}\left(N^{\rho-\mu} y_{i}\right)^{\frac{1}{\mu}}\right)^{\mu}$. This function is discontinuous with respect to the introduction of a new good. However, the discontinuity disappears if we assume a continuous goods space.
} 
as assumed in Rotemberg and Woodford (1995). They motivate constant returns as a normalization, but this assumption is a restriction rather than a normalization.

The aggregator is assumed to maximize its profit:

$$
\Pi=P Y-\sum_{i=1}^{N} p_{i} y_{i}
$$

where all price variables are exogenous to the aggregator and the aggregate price index is defined as: ${ }^{11}$

$$
P=N^{-(\rho-\mu)}\left(\sum_{i=1}^{N} p_{i}^{-\frac{1}{\mu-1}}\right)^{-(\mu-1)}
$$

The first order condition with respect to $y_{i}$ reduces to a constant-elasticity inverse demand function:

$$
p_{i}=P N^{\left(\frac{\rho-\mu}{\mu}\right)}\left(\frac{y_{i}}{Y}\right)^{-\frac{\mu-1}{\mu}} .
$$

Note that the new parameter, $\rho$, affects only the level of the demand without affecting its elasticity. Hence the first order conditions of the firms, Eqs. (2) and (3), are not sensitive to the parameterization of returns to variety.

Besides aggregating differentiated goods, macroeconomics has also made it a convention to scrutinize a symmetric equilibrium under identical technologies of the firms. The homogeneity of capital and labor implies the following relations in equilibrium:

$$
K=N k, L=N l,
$$

where $K$ and $L$ denote aggregate capital and aggregate labor, respectively.

\subsection{Returns to Scale}

Based upon previous discussions on firms' behavior and aggregation, we now derive the aggregate reduced-form production function, i.e. an aggregate version of firms' technology with a zero-profit condition imposed. Aggregation of homogeneous inputs in Eq. (9), together with aggregation of outputs as shown in Eq. (7), transforms the firms' technologies, Eq. (1), as follows:

$$
Y=N^{(\rho-\gamma)}\left(K^{\alpha} L^{1-\alpha}\right)^{\gamma}-N^{\rho} \phi
$$

\footnotetext{
${ }^{11}$ At symmetry, $P=\frac{1}{N^{(\rho-1)}} p$. Increasing returns to variety imply that an increase in the number of firms leads to a decrease in the price index due to an efficiency gain. See Feenstra (1994) for an application to import goods. Existing price indices do not adjust benefits to variety: they assume $\rho=1$.
} 
This is the aggregate structural production function. Both the aggregate gross output and the aggregate fixed cost feature an element of returns to variety due to aggregation. Note that we have not yet imposed a zero-profit condition, which is a part of the equilibrium conditions. That is, the aggregate production function in a reduced form is derived only after the zero-profit condition is imposed.

We now derive what the zero-profit condition, Eq. (4), implies for the aggregate reduced-form production function. The relationship between individual and aggregate inputs transforms the zero-profit condition as follows:

$$
\phi N^{\gamma}=\left(1-\frac{\gamma}{\mu}\right)\left(K^{\alpha} L^{1-\alpha}\right)^{\gamma} .
$$

Note that this does not involve the degree of returns to variety, $\rho$. This aggregate version of the zero-profit condition has been interpreted in two different ways in the literature.

The first interpretation endogenizes the number of firms, $N$, as a function of the aggregate variables as follows:

$$
N=\left(\frac{\left(1-\frac{\gamma}{\mu}\right)}{\phi}\right)^{\frac{1}{\gamma}} K^{\alpha} L^{1-\alpha} .
$$

If there is a change in the economy causing a positive profit, e.g. a positive productivity shock, the number of firms increases to take advantage of this change, thus reducing profits to zero. The fixed cost of a firm is assumed to remain constant. Rotemberg and Woodford (1995) and Devereux, Head and Lapham (1996a,b) adopt this interpretation. This interpretation has a conceptual problem associated with the definition of the equilibrium, since an equilibrium with entry and exit involves a change of the goods space. ${ }^{12}$

Conversely, the second interpretation considers the fixed cost as an endogenous variable, that is:

$$
\phi=N^{-\gamma}\left(1-\frac{\gamma}{\mu}\right)\left(K^{\alpha} L^{1-\alpha}\right)^{\gamma} .
$$

Taken literally, a firm's fixed cost increases with aggregate inputs and is also affected by the market structure represented by the degree of market power, $\mu$. This interpretation has been less attractive than the former, since the amount of the fixed cost is not a technological parameter but a function of other parameters and exogenous variables. ${ }^{13}$

\footnotetext{
${ }^{12}$ See Benassy (1991) for the details.

${ }^{13}$ The endogeneity with respect to the degree of market power might be rationalized by the argument that a larger fixed cost (e.g. advertising) should be paid at each period in an economy with a larger degree of market power.
} 
However, an increase in the fixed cost per firm is equivalent to job creation on the intensive margin. That is, output per firm is proportional to the fixed cost. Furthermore, over low frequencies of a growing economy, it is reasonable to assume that fixed costs grow as firm size grows over time. No papers have argued for this interpretation seriously, but some follow this interpretation implicitly by assuming that the number of firms is constant. If the number of firms is assumed to be constant, as in Hornstein (1993), Yun (1996), and Beaudry and Devereux (1995a), the only way to achieve the zero-profit condition is by endogenizing the fixed cost of a firm.

As with the specification of the aggregator, there is no a priori reason to prefer either interpretation. In general, both the fixed cost and the number of firms may change. This paper, first in the literature, incorporates this generality by defining an additional parameter, $\varepsilon \in[0,1]$, which represents the ratio of the intensive and extensive margins. Our parameterization postulates the fixed cost and the number of firms as follows: ${ }^{14}$

$$
\begin{aligned}
\phi & =\frac{1}{\kappa}\left[\left(1-\frac{\gamma}{\mu}\right)\left(K^{\alpha} L^{1-\alpha}\right)^{\gamma}\right]^{\varepsilon}, \\
N^{\gamma} & =\kappa\left[\left(1-\frac{\gamma}{\mu}\right)\left(K^{\alpha} L^{1-\alpha}\right)^{\gamma}\right]^{1-\varepsilon},
\end{aligned}
$$

where $\kappa$ is an arbitrary constant. This constant affects only the level of variables, but not their percentage deviation. We can interpret the parameter $\varepsilon$ as one related with the elasticity of supplying new firms. Manipulating Eqs. (14) and (15), we have a constant-elasticity supply schedule,

$$
N^{\gamma \varepsilon}=\kappa \phi^{1-\varepsilon}
$$

where $\phi$ is interpreted as the marginal cost of some specialized resource, e.g. entrepreneurial ability, required to create a new firm. For example, when $\varepsilon=0$, the supply of entrepreneurial ability is infinitely elastic at a price of $\phi$ per unit.

Note that the extreme cases of $\varepsilon=0$ and $\varepsilon=1$ correspond to the two interpretations in the literature, Eqs. (12) and (13). This paper shows that our generalization is analytically tractable and gives intuition for the interaction among the various increasing returns. Before discussing the general case containing the parameter $\varepsilon$, we consider the two extreme cases.

\footnotetext{
${ }^{14}$ This parameterization of endogenous fixed costs can be reconciled with that of exogenous fixed costs, when negative externalities are introduced via fixed costs as in Appendix D. Optimal decision of fixed cost in industrial-organization literature endogenizes the $\varepsilon$ parameter, but constant $\varepsilon$ is not a bad approximation when time unit if constant.
} 
Suppose that the number of firms is endogenous, i.e. $\varepsilon=0$, then the aggregate output in equilibrium is derived by substituting Eq. (12) into Eq. (10):

$$
Y_{\phi}=\phi^{-\left(\frac{\rho}{\gamma}-1\right)} \frac{\gamma}{\mu}\left(1-\frac{\gamma}{\mu}\right)^{\left(\frac{\rho}{\gamma}-1\right)}\left(K^{\alpha} L^{1-\alpha}\right)^{\rho} .
$$

In this case, $\rho$, the degree of returns to variety, determines the degree of aggregate returns to scale. The intuition behind this is that the firm size is constant while the number of firms is variable. Since the endogenous number of firms is proportional to the constant-returns-to-scale term $\left(K^{\alpha} L^{1-\alpha}\right)$ in Eq. (12), the channel of returns to variety works while overriding that of diminishing marginal cost. Note that the economy may produce more output with a larger fixed cost. If $\rho$ is smaller than $\gamma$, output increases as the fixed cost increases. This apparently abnormal result comes from the following intuition: since the degree of diminishing marginal cost is higher than that of returns to variety, it is better to have larger firms. The gains from larger firms offset the losses from a larger aggregate fixed cost.

However, if we assume an endogenous fixed cost, i.e. $\varepsilon=1$, then the aggregate output behaves differently. Using Eq. (13), the aggregate technology of Eq. (10) is transformed as follows:

$$
Y_{N}=N^{(\rho-\gamma)} \frac{\gamma}{\mu}\left(K^{\alpha} L^{1-\alpha}\right)^{\gamma}
$$

Note that the degree of returns to scale is $\gamma$, the degree of diminishing marginal cost. Opposite from the previous case of an endogenous number of firms, the channel of diminishing marginal cost is in effect while there is no effect of the returns to variety. In a sense, this is trivial since the number of firms is constant. A firm's output and fixed cost move proportionally with the aggregate output. Inputs per firm move also proportionally with the aggregate inputs. Note that an increase in the number of firms may increase or decrease the aggregate output, depending on the sign of $(\rho-\gamma)$. If the degree of returns to variety is higher than that of diminishing marginal cost, it is better to have more firms in the economy.

Now let's consider our general case where both the fixed cost and the number of firms change according to Eqs. (14) and (15). It is natural to speculate that the degree of returns to scale is between the two extreme cases. Substituting Eqs. (14) and (15) into Eq. (10), the aggregate production function in a reduced form is simplified as follows:

$$
Y_{\kappa}=\kappa^{\left(\frac{\rho}{\gamma}-1\right)}\left(1-\frac{\gamma}{\mu}\right)^{(1-\varepsilon)\left(\frac{\rho}{\gamma}-1\right)} \frac{\gamma}{\mu}\left(K^{\alpha} L^{1-\alpha}\right)^{\varepsilon \gamma+(1-\varepsilon) \rho} .
$$

The degree of returns to scale in this general case is $[\varepsilon \gamma+(1-\varepsilon) \rho]$, a convex combination of $\gamma$ and $\rho$. The degree of returns to scale in the aggregate economy depends 
on the choice of three parameters representing diminishing marginal cost $(\gamma)$, returns to variety $(\rho)$, and the ratio of the two endogenous changes $(\varepsilon)$. Note that increasing returns at a firm level due to positive fixed costs does not generate increasing returns at an aggregate level.

The effect of monopolistic competition on the aggregate output is now clear. Both the fixed cost and the number of firms are an increasing function of the degree of market power, $\mu$. Since a larger degree of market power means a larger profit, we need more firms and a larger fixed cost per firm to reduce the profit to zero. Given a certain amount of the aggregate inputs, a higher degree of market power decreases the amount of differentiated output due to an increase in the fixed cost and a decrease in inputs per firm. However, if the number of firms is endogenous $(\varepsilon<1)$ and the degree of returns to variety is larger than that of diminishing marginal cost $(\rho>\gamma)$, an offsetting mechanism is at work, since a higher degree of market power increases the number of firms. ${ }^{15}$ This mechanism overturns the decrease in a firm's output if the degree of market power is lower than the degree of aggregate returns to scale, $[\varepsilon \gamma+(1-\varepsilon) \rho]$. In other words, an economy with monopolistic competition would produce maximum output if the degree of market power were equal to the degree of returns to scale. The $\cap$-shaped graph in the first plot of Figure 1 on page 27, denoted as $Y^{m}$, shows this property. For example, in a model with a Dixit-Stiglitz aggregator $(\mu=\rho)$ and an endogenous number of firms $(\varepsilon=0)$, the monopolistic-competition economy is optimal in the sense that it produces the most aggregate output. This optimality pertains to the comparison among different market economies and has nothing to do with the comparison with a social planner, which will be discussed later.

Before moving on to a dynamic model, we analyze the mechanics of input prices. The profit maximizations of the firms have implications for the rental rate and the wage, Eqs. (2) and (3), which result in the following aggregate relations:

$$
\begin{aligned}
Z & =\alpha \frac{Y}{K}, \\
W & =(1-\alpha) \frac{Y}{L} .
\end{aligned}
$$

Although the dynamics of input prices depend on gross output, they mimic those of net output because the aggregate fixed cost is proportional to the aggregate gross output, and so the net output. However, this property does not extend to a dynamic case. This point turns out to be important in the discussion of identification issues.

\footnotetext{
${ }^{15} \mathrm{It}$ is easy to check that the aggregate output is decreasing over the whole range of the degree of market power if both conditions do not hold.
} 


\subsection{A Dynamic Model}

Up to now, neither the size of the fixed cost nor the degree of market power affects the degree of returns to scale. Then, is there no point of introducing monopolistic competition and the fixed cost in the behavior of returns to scale? Yes, the presence of the fixed cost does affect returns to scale in a dynamic model where adjustments to zero profit are not instantaneous. Note that the static case considered above is analogous to the Marshallian long run, in that no specialized resource prevents zero profits from being achieved. Following the same spirit, we interpret a dynamic case considered below as the Marshallian short run since existing firms may earn quasi-rents.

To consider a dynamic case, the aggregate technology without the zero-profit condition imposed, Eq. (10), is rewritten with time subscripts for the variables.

$$
Y_{t}=N_{t}^{(\rho-\gamma)}\left(K_{t}^{\alpha} L_{t}^{1-\alpha}\right)^{\gamma}-N_{t}^{\rho} \phi_{t}
$$

This structural production function does not directly involve the degree of market power, $\mu$. However, this degree representing the market structure may affect the degree of returns to scale of the aggregate reduced-form production function in a dynamic model.

Apart from the choice of endogenous variables in a static model, an additional consideration arises in a dynamic model: how fast does the economy move towards the state of zero profits? Two extreme cases have been considered in the literature. In the case of full adjustment, profit is zero at every period. This specification is used in Devereux, Head and Lapham (1996a,b). The short-run dynamics are the same as that of the static model described in Eqs. (16)-(18). The other extreme is the case of no short-run adjustment. Profit is zero only at the steady state, so the short-run dynamics of the fixed cost and the number of firms are not affected even if profit is not zero in a particular period. Hornstein (1993) and Beaudry and Devereux (1995a) adopt this specification. In this case, returns to scale are governed by neither diminishing marginal cost nor returns to variety. They are governed by the degree of market power, which is a function of the degree of substitution among differentiated goods. These two extreme cases are compared in Chatterjee and Cooper (1993).

Another contribution in this paper is to generalize the specification of zero profits by introducing an additional parameter, $\beta \in[0,1]$, representing the speed of adjustments. ${ }^{16}$ This speed is inversely related to cost of adjustments, e.g. entry and exit.

\footnotetext{
${ }^{16}$ Rotemberg and Woodford (1995) is the only example which does not follow one of the two extreme cases. The calibration corresponds to a very small $\beta$ of this paper. Optimal decision of
} 
We assume that the fixed cost and the number of firms adjust period by period, but not fast enough to achieve zero profit at every period: ${ }^{17}$

$$
\begin{aligned}
\phi_{t} & =(\tilde{\phi})^{\beta} \bar{\phi}^{(1-\beta)}, \\
N_{t} & =(\tilde{N})^{\beta} \bar{N}^{(1-\beta)},
\end{aligned}
$$

where $(\tilde{\phi}, \tilde{N})$ guarantees zero profit at every period and $(\bar{\phi}, \bar{N})$ guarantees zero profit at the exogenous steady state. Note that no adjustment corresponds to the case when $\beta=0$, and full adjustment, when $\beta=1$.

Specifically, the four variables are defined as follows:

$$
\begin{aligned}
\tilde{\phi} & =\frac{1}{\tilde{\kappa}}\left[\left(1-\frac{\gamma}{\mu}\right)\left(K_{t}^{\alpha} L_{t}^{1-\alpha}\right)^{\gamma}\right]^{\tilde{\varepsilon}}, \\
\bar{\phi} & =\frac{1}{\bar{\kappa}}\left[\left(1-\frac{\gamma}{\mu}\right)\left(\bar{K}^{\alpha} \bar{L}^{1-\alpha}\right)^{\gamma}\right]^{\bar{\varepsilon}}, \\
\tilde{N}^{\gamma} & =\tilde{\kappa}\left[\left(1-\frac{\gamma}{\mu}\right)\left(K_{t}^{\alpha} L_{t}^{1-\alpha}\right)^{\gamma}\right]^{1-\tilde{\varepsilon}}, \\
\bar{N}^{\gamma} & =\bar{\kappa}\left[\left(1-\frac{\gamma}{\mu}\right)\left(\bar{K}^{\alpha} \bar{L}^{1-\alpha}\right)^{\gamma}\right]^{1-\bar{\varepsilon}} .
\end{aligned}
$$

We will see that only $\tilde{\varepsilon}$, a parameter regarding zero profit at every period, matters for the dynamics of the model. The other parameter, $\bar{\varepsilon}$, affects only the steady-state properties. Alternatively, the speed of adjustments can vary between the fixed cost and the number of firms with the assumption that $\tilde{\varepsilon}=\bar{\epsilon}$. In this case, the three parameters are $\left(\varepsilon, \beta_{\phi}, \beta_{N}\right)$. However, this new model is equivalent to our model with the parameters defined as follows:

$$
\beta=\varepsilon \beta_{\phi}+(1-\varepsilon) \beta_{N}, \tilde{\varepsilon}=\frac{\beta_{\phi}}{\beta} \varepsilon, \bar{\varepsilon}=\frac{1-\beta_{\phi}}{1-\beta} \varepsilon .
$$

Substituting Eqs. (20)-(23) into Eq. (19), the aggregate reduced-form production function in the dynamic model is as follows:

$$
Y_{t}=\kappa_{1}\left[K_{t}^{\alpha} L_{t}^{1-\alpha}\right]^{\beta(\tilde{\varepsilon} \gamma+(1-\tilde{\varepsilon}) \rho)+(1-\beta) \gamma}-\kappa_{2}\left[K_{t}^{\alpha} L_{t}^{1-\alpha}\right]^{\beta(\tilde{\varepsilon} \gamma+(1-\tilde{\varepsilon}) \rho)},
$$

entry and exit in industrial-organization literature endogenizes the $\beta$ parameter, but constant $\beta$ is an approximation under constant time unit. A higher frequency would imply a lower $\beta$.

${ }^{17}$ Our specification with an additional parameter preserves the simple one-period nature of the model. The model becomes intertemporal if we introduce partial adjustments by assuming the fixed cost and the number of firms predetermined, as in Ambler and Cardia (1996). 
where

$$
\begin{aligned}
& \kappa_{1}=\left(\tilde{\kappa}^{\beta} \bar{\kappa}^{1-\beta}\right)^{\left(\frac{\rho}{\gamma}-1\right)}\left(1-\frac{\gamma}{\mu}\right)^{[\beta(1-\tilde{\varepsilon})+(1-\beta)(1-\bar{\varepsilon})]\left(\frac{\rho}{\gamma}-1\right)}\left[\bar{K}^{\alpha} \bar{L}^{1-\alpha}\right]^{(1-\beta)(1-\bar{\varepsilon})(\rho-\gamma)}, \\
& \kappa_{2}=\left(\tilde{\kappa}^{\beta} \bar{\kappa}^{1-\beta}\right)^{\left(\frac{\rho}{\gamma}-1\right)}\left(1-\frac{\gamma}{\mu}\right)^{\beta \frac{\tilde{\varepsilon} \gamma+(1-\tilde{\varepsilon}) \rho}{\gamma}+(1-\beta) \frac{\bar{\varepsilon} \gamma+(1-\bar{\varepsilon}) \rho}{\gamma}}\left[\bar{K}^{\alpha} \bar{L}^{1-\alpha}\right]^{(1-\beta)(\bar{\varepsilon} \gamma+(1-\bar{\varepsilon}) \rho)} .
\end{aligned}
$$

Note that the two exponent terms in Eq. (24) are different from each other and that neither of them involves the degree of market power, $\mu$. Gross output fluctuates strictly more than the aggregate fixed cost, unless adjustments are instantaneous. This nonlinear reduced-form production function has such complicated dynamics that it cannot be compared with the static case. However, in a linearized version of the dynamic model, the behavior of the variables is comparable to the static model. In practice, most DSGE papers use a linearized version.

The log-linearized version of Eq. (24) is:

$$
\hat{Y}_{t}=[\beta(\tilde{\varepsilon} \gamma+(1-\tilde{\varepsilon}) \rho)+(1-\beta) \mu]\left(\alpha \hat{K}_{t}+(1-\alpha) \hat{L}_{t}\right)
$$

where $\hat{x}_{t}$ is the percentage deviation of $x_{t}$ from its steady state. This clearly shows that market structure affects output fluctuations in a way indistinguishable from the two previous sources of increasing returns, diminishing marginal cost and increasing returns to variety. The degree in the dynamic case is a convex combination of the degree of the static case in Eq. $(16),[\tilde{\varepsilon} \gamma+(1-\tilde{\varepsilon}) \rho]$, and the degree of market power, $\mu$. Equivalently, the degree of returns to scale is a convex combination of the three parameters: the degree of diminishing marginal cost $(\gamma)$, the degree of returns to variety $(\rho)$, and the degree of market power $(\mu)$. Note that the degree of returns to scale in the long run, i.e. at the steady state, would be $[\bar{\varepsilon} \gamma+(1-\bar{\varepsilon}) \rho]$ which is different from that of the short run in Eq. (25). This helps explain the difference between low- and high-frequency fluctuations, both of which are important in macroeconomics.

In the extreme case where there is no period-by-period adjustment, the degree of short-run returns to scale is the degree of market power; the other two parameters do not enter at all. The intuition of this extreme case is as follows. Since aggregate fixed cost does not respond to the change of aggregate inputs, net aggregate output fluctuates more than gross aggregate output. Furthermore, the amount firms produce relative to the size of the fixed cost depends on the degree of market power. The result of this extreme case shows that the introduction of diminishing marginal cost in Hornstein (1993) and Beaudry and Devereux (1995a) does not affect the dynamics of the aggregate reduced-form production function. However, 
this does not mean that the introduction has no influence on the dynamics of a general-equilibrium model at all. The degree of diminishing marginal cost affects the dynamics of input prices as follows.

In a dynamic case, the dynamics of the rental rate and the wage are as follows:

$$
\begin{aligned}
Z_{t} & =\alpha\left(\frac{\gamma}{\mu}\right) \frac{\kappa_{1}\left[K_{t}^{\alpha} L_{t}^{1-\alpha}\right]^{\beta(\tilde{\varepsilon} \gamma+(1-\tilde{\varepsilon}) \rho)+(1-\beta) \gamma}}{K_{t}}, \\
W_{t} & =(1-\alpha)\left(\frac{\gamma}{\mu}\right) \frac{\kappa_{1}\left[K_{t}^{\alpha} L_{t}^{1-\alpha}\right]^{\beta(\tilde{\varepsilon} \gamma+(1-\tilde{\varepsilon}) \rho)+(1-\beta) \gamma}}{L_{t}} .
\end{aligned}
$$

Regardless of the assumption about adjustments, the degree of market power does not affect the dynamics of the input prices. The dynamic properties of input prices are governed by those of gross output rather than net output, since fixed costs and the number of firms are exogenous to the firm's input decision. For example, in models where the presence of fixed costs is the only source of increasing returns as in Hornstein (1993) and Rotemberg and Woodford (1995), the introduction of monopolistic competition and increasing returns does not affect the dynamics of input prices as a function of aggregate inputs.

Note that the exponent term relevant for the input-price dynamics is strictly smaller than that of the aggregate returns to scale, unless the adjustments are instantaneous. ${ }^{18}$ This difference has an implication for deriving indeterminacy from increasing returns to scale, as in Benhabib and Farmer (1994). Since the dynamics of the input prices are critical for the existence of indeterminacy, all sources of increasing returns do not contribute to its existence. Of the three sources, the degree of market power has nothing to do with the existence of indeterminacy.

The bottom line of the model is as follows. The degree of returns to scale of the aggregate reduced-form production function is a convex combination of three parameters: the degree of diminishing marginal cost, the degree of returns to variety, and the degree of market power. The weights depend on the specification of a zeroprofit condition. Unless zero profit is imposed period by period, the dynamics of input prices have information independent of the aggregate reduced-form production function.

\footnotetext{
${ }^{18}$ In other words, even if we have the dynamics of output and each input, we do not derive the dynamics of the input prices. The dynamics of the input prices have some independent implications.
} 


\section{Implications}

This section derives implications of the model and, based upon them, reviews and critiques existing literature. The model is related to two branches of empirical literature. A direct implication comes from the behavior of the aggregate reducedform production function. The DSGE literature on monopolistic competition uses a specific parameterization of this paper. Our general model in this paper gives a warning sign to both calibration and estimation approaches. Another implication of the model involves the works using disaggregate data to identify some parameters. This paper gives interpretations for the estimates this literature have found, different from how they used to be interpreted. In addition to these empirical implications, this paper derives welfare implications. We compare an economy of monopolistic competition with a social planner's economy and find that some previous welfare results are due to restricted specifications.

\subsection{Identification with Aggregate Data}

To facilitate the discussion of identification issues, we begin by comparing the specifications of how the existing literature parameterizes the speed of adjustments $(\beta)$ and the period-by-period endogeneity between the fixed cost and the number of firms $(\tilde{\varepsilon})$. For convenience, recall that the degree of returns to scale of the aggregate reducedform production function is $[\beta(\tilde{\varepsilon} \gamma+(1-\tilde{\varepsilon}) \rho)+(1-\beta) \mu]$. Therefore, this value is of sole importance in determining the aggregate dynamics of the production function. The dynamics of input prices are governed by $[\beta(\tilde{\varepsilon} \gamma+(1-\tilde{\varepsilon}) \rho)+(1-\beta) \gamma]$, the degree of returns to scale of aggregate gross output.

Hornstein (1993) and Beaudry and Devereux (1995a) assume that only the fixed cost is endogenous and that the adjustment to zero profit occurs only at the steady state. Since the resulting degree of aggregate returns is $\mu$, diminishing marginal cost and increasing returns to variety do not affect the dynamics of the aggregate reduced-form production function. However, this does not mean that, in a particular general-equilibrium model, the dynamics of output depend only on the degree of market power. Since the dynamics of input prices depend on diminishing marginal cost and returns to variety, they also affect output in a general-equilibrium model. ${ }^{19}$ In Rotemberg and Woodford (1995), the endogenous variable is not the fixed cost but the number of firms. However, this does not make much difference because their calibrated speed of adjustments is very low, a small $\beta$. If the responses of the number

\footnotetext{
${ }^{19}$ For example, the second and the third cases of Hornstein (1993) do not produce the same results even if the only difference between the two cases lies in the degree of diminishing marginal cost.
} 


\begin{tabular}{|c|c|c|}
\hline$\tilde{\varepsilon} \backslash \beta$ & 0 & 1 \\
\hline 0 & Rotemberg and Woodford (1995) & Devereux, Head and Lapham (1996a,b,c) \\
\hline 1 & Hornstein (1993) & \\
\hline
\end{tabular}

Table 1: Examples of Specification

of firms happen only at the steady state, a zero $\beta$, then different assumptions on endogeneity do not make any difference at all.

The endogeneity of the number of firms matters if the zero-profit condition is imposed period by period, as in Devereux, Head and Lapham (1996a,b,c). The dynamics of both output and input prices depend on the degree of returns to variety. The degree of diminishing marginal cost and that of market power do not affect the properties of the variables, as far as the percentage deviations are concerned. Table 1 summarizes the specifications. The first column corresponds to a model where adjustments to zero profit occur only at the steady state. ${ }^{20}$ The second column contains the static version of this paper, where returns to variety matters. The first and the second rows correspond to models of endogenous number of firms and endogenous fixed cost, respectively.

Discussion of econometric issues such as identification naturally involves the specification of an error structure. A convention is to interpret the productivity shocks as a random variable. Accordingly, this section restores the notation for productivity shocks, $A_{t}$. Note that identification issues can be discussed only in the context of a specific model and available data. From the calibration point of view, identification issues are interpreted as follows. If the model is not identified, different parameter calibrations may result in the same model.

Suppose that our model is the aggregate reduced-form production function with exogenous steady states and that we have aggregate data on output, capital and labor. Augmenting the linearized aggregate reduced-form production function, Eq. (25), with productivity shocks as an error structure, we have:

$$
\hat{Y}_{t}=[\beta(\tilde{\varepsilon} \gamma+(1-\tilde{\varepsilon}) \rho)+(1-\beta) \mu]\left(\alpha \hat{K}_{t}+(1-\alpha) \hat{L}_{t}+\frac{1}{\gamma} \hat{A}_{t}\right) .
$$

Using the aggregate data, we can draw inferences about the share parameter, $\alpha$, and the aggregate returns to scale, $[\beta(\tilde{\varepsilon} \gamma+(1-\tilde{\varepsilon}) \rho)+(1-\beta) \mu]$. The three parameters representing the degrees are not identified separately. From the calibration point

\footnotetext{
${ }^{20}$ Rotemberg and Woodford (1995) is included in this category since $\beta$ is very small, even if not exactly zero.
} 
of view, different parameter calibrations may result in the same aggregate returns to scale. For example, the dynamic properties of Rotemberg and Woodford (1995) with slow period-by-period adjustments, i.e. a small nonzero $\beta$, can be replicated by another economy where adjustments occur only at the steady state, i.e. zero $\beta$. Since the fixed cost is exogenous $(\tilde{\varepsilon}=0)$, the degree of aggregate returns to scale is $[\beta \rho+(1-\beta) \mu]$. Because the degree of returns to variety is normalized to 1 , an appropriate decrease in the degree of market power by $\beta(\mu-1)$ is the only modification necessary in the new economy without any short-run adjustments. The dynamic behavior of all the aggregate variables, except for the gross output and the number of firms, is the same as that of the original model.

More aggregate data may solve the identification problem. Data on the fixed cost or the number of firms would be helpful. However, it is not likely that we can get measures of these two variables, consistent with this paper. Now suppose that we have additional data on the rental rate or the wage and that the model also includes the appropriate input-price equation, Eq. (26) or (27). The new model identifies another linear combination of parameters, $[\beta(\tilde{\varepsilon} \gamma+(1-\tilde{\varepsilon}) \rho)+(1-\beta) \gamma] .{ }^{21}$ This is different from the degree of aggregate returns and so the model identifies two parameters, unless adjustments are instantaneous. For example, the two free parameters estimated in Kim (1996) are $\gamma$ and $\mu$, both of which are identified for the following reason. Since adjustments are assumed to occur only at the steady state, the degree of aggregate returns is $\mu$ and the dynamics of input prices are governed by $\gamma$. Additional data on the interest rate provide information on the rental rate and so $\gamma$ is also identified.

Considering the identification problems, one may wonder why we care about various increasing returns separately. This question will be answered when the market economy is compared with a social planner. We will show that different increasing returns have different normative implications. Before comparing with a social planner, we review the literature using disaggregate data to identify some parameters of the model.

\subsection{Interpretation of Disaggregate Data}

Recall that the aggregate economy has been derived from a firm's problem. If we interpret a firm as a particular sector of the economy, the data disaggregated to the sectoral level have implications on the state of the economy. Two related literatures apply this interpretation. Here, we evaluate the implications of these literatures by

\footnotetext{
${ }^{21}$ Note that the replication of Rotemberg and Woodford (1995) in the previous paragraph does not change input-price dynamics. Since both $\gamma$ and $\rho$ are equal to 1 , the change in $\beta$ does not change the dynamics.
} 
using our general specification of increasing returns in a monopolistic-competition model.

Firm's first order conditions are the starting point of testing the joint hypothesis of perfectly competitive markets and constant returns to scale, as in Hall (1996, 1998, 1990). However, compared with the model in this paper, they do not incorporate a zero-profit condition. Since it is assumed that there are no fixed costs, there is no difference between the structural production function and its reduced form. The log-linearized production function is:

$$
\frac{d y_{i t}}{y_{i t}}=\gamma_{i}\left(\alpha_{i} \frac{d k_{i t}}{k_{i t}}+\left(1-\alpha_{i}\right) \frac{d l_{i t}}{l_{i t}}\right)+\frac{d A_{i t}}{A_{i t}} .
$$

The analysis of Hall $(1986,1988,1990)$ is based on the measurement of productivity growth in Solow (1957). Calculation of the Solow residual requires the revenue share:

$$
s_{R}=\frac{W_{t} l_{i t}}{p_{i t} y_{i t}} .
$$

Without zero-profit conditions or fixed costs, the revenue share is equal to $\frac{\gamma_{i}}{\mu}\left(1-\alpha_{i}\right)$. Therefore, the Solow residual is:

$$
\frac{d y_{i t}}{y_{i t}}-s_{R} \frac{d l_{i t}}{l_{i t}}-\left(1-s_{R}\right) \frac{d k_{i t}}{k_{i t}}=(\mu-1) s_{R}\left(\frac{d l_{i t}}{l_{i t}}-\frac{d k_{i t}}{k_{i t}}\right)+\left(\gamma_{i}-1\right) \frac{d k_{i t}}{k_{i t}}+\frac{d A_{i t}}{A_{i t}} .
$$

This is the basis of testing for the joint hypothesis of perfect competition $(\mu=1)$ and constant returns to scale $\left(\gamma_{i}=1\right)$.

Hall (1990) proposes a way to differentiate diminishing marginal cost from market power. He defines a new share as follows:

$$
s_{C}=\frac{W_{t} l_{i t}}{Z_{t} k_{i t}+W_{t} l_{i t}} .
$$

This is called the cost share, since it is the share of labor input in total cost, rather than in total revenue as in Eq. (28). Note that it is equal to the share parameter, $\left(1-\alpha_{i}\right)$, regardless of increasing returns and market power. The cost-based residual is as follows:

$$
\frac{d y_{i t}}{y_{i t}}-s_{C} \frac{d l_{i t}}{l_{i t}}-\left(1-s_{C}\right) \frac{d k_{i t}}{k_{i t}}=\left(\gamma_{i}-1\right)\left(s_{C} \frac{d l_{i t}}{l_{i t}}+\left(1-s_{C}\right) \frac{d k_{i t}}{k_{i t}}\right)+\frac{d A_{i t}}{A_{i t}} .
$$

Unlike the Solow residual, the cost-based residual can provide information only on increasing returns. ${ }^{22}$ This algebra lets Hall (1990) conclude that his evidence points in the direction of increasing returns, presumably coupled with market power.

\footnotetext{
${ }^{22}$ The similar results for the Solow residual and the cost-based residual support the absence of profits in Hall (1990). Note that a zero-profit condition is not imposed.
} 
However, this difference between the Solow residual and the cost-based residual disappears under the specification of this paper which incorporates fixed costs and zero-profit conditions. First order conditions imply that the steady state of the revenue share is the share parameter. The cost share is the share parameter regardless of the specification. Considering that the fixed cost does not adjust instantaneously, the firm-level reduced-form production function is log-linearized as follows:

$$
\frac{d y_{i t}}{y_{i t}}=\left[\beta \tilde{\varepsilon} e \gamma_{i}+(1-\beta \tilde{\varepsilon} e) \mu\right]\left(\alpha_{i} \frac{d k_{i t}}{k_{i t}}+\left(1-\alpha_{i}\right) \frac{d l_{i t}}{l_{i t}}\right)+\text { error },
$$

where $e$ represents the elasticity of aggregate inputs with respect to firm inputs. ${ }^{23}$ The formula for both the Solow residual and the cost-based residual is:

$$
\frac{d y_{i t}}{y_{i t}}-s \frac{d l_{i t}}{l_{i t}}-(1-s) \frac{d k_{i t}}{k_{i t}}=\left[\beta \tilde{\varepsilon} e \gamma_{i}+(1-\beta \tilde{\varepsilon} e) \mu-1\right]\left(s \frac{d l_{i t}}{l_{i t}}+(1-s) \frac{d k_{i t}}{k_{i t}}\right)+\text { error, }
$$

where $s$ represents both $s_{R}$ and $s_{C}$. Since the revenue share is equal to the share parameter only at the steady state, this formula holds only approximately for the cost-based residual. Since the cost-based residual provides the same information as the Solow residual, the way proposed in Hall (1990) cannot identify the degree of diminishing marginal cost separately from that of market power.

While Hall $(1986,1988,1980)$ incorporates first order conditions in his analysis, others study increasing returns directly by regressing outputs on inputs, using Eq. (29) as a regression equation. ${ }^{24}$ It would be realistic to assume that $\beta \tilde{\varepsilon} e$ is close to zero, since all three terms are likely to be small. Furthermore, this assumption is true for all existing specifications summarized in Table 1. Under this assumption, the literature can give information only on the market structure. In equilibrium, the degree of market power is a mixture of two sources of increasing returns at a firm level: diminishing marginal cost and the presence of fixed costs. The two sources cannot be separately identified by production function regressions which use a reduced form. However, most DSGE papers arguing for or against the existence of indeterminacy draw information on diminishing marginal cost from this literature. This is valid only when there is no fixed cost in the economy. We can discuss the existence of indeterminacy only after identifying the degree of diminishing marginal cost separately from that of market power. Furthermore, as we will show shortly, this separate identification is important from a welfare perspective.

\footnotetext{
${ }^{23}$ The elasticity is: $e=\alpha \frac{d K_{t}}{d k_{i t}} \frac{k_{i t}}{K_{t}}+(1-\alpha) \frac{d L_{t}}{d l_{i t}} \frac{l_{i t}}{L_{t}}$.

${ }^{24}$ For a detailed discussion and the references, see Basu and Fernald (1997).
} 


\subsection{Comparison with a Social Planner}

A basic issue of welfare economics is whether a market solution will yield the social optimum or not. Unlike the case of monopolistic competition, the zero-profit condition is not binding for a social planner. So the planner's problem is static in the sense that there is no concern about the speed of adjustments. For ease of comparison, adjustments to zero profits are assumed to be instantaneous in the economy of monopolistic competition, i.e. $\beta=1$, and so time subscripts are suppressed. The behavior of the market economy is summarized as follows:

$$
\begin{aligned}
\phi^{\text {market }} & =\left(1-\frac{\gamma}{\mu}\right)^{\varepsilon}\left(K^{\alpha} L^{1-\alpha}\right)^{\varepsilon \gamma}, \\
N^{\text {market }} & =\left(1-\frac{\gamma}{\mu}\right)^{\frac{1-\varepsilon}{\gamma}}\left(K^{\alpha} L^{1-\alpha}\right)^{1-\varepsilon}, \\
Y^{\text {market }} & =\frac{\gamma}{\mu}\left(1-\frac{\gamma}{\mu}\right)^{(1-\varepsilon)\left(\frac{\rho}{\gamma}-1\right)}\left(K^{\alpha} L^{1-\alpha}\right)^{\varepsilon \gamma+(1-\varepsilon) \rho},
\end{aligned}
$$

where the level parameter, $\kappa$, is normalized to 1 in the original equations, Eq. (14), (15) and (16). The superscripts of 'market' denote the market economy of monopolistic competition.

Note that the planner's optimization problem with respect to the fixed cost is not well-defined. For the planner, it is optimal to decrease the fixed cost as close to zero as possible. So the welfare issues are considered only under the assumption that the social planner is not allowed to control the fixed cost. Given a process of the fixed cost, the number of firms in an economy is chosen by the social planner whose objective is:

$$
\max _{N}\left[N^{(\rho-\gamma)}\left(K^{\alpha} L^{1-\alpha}\right)^{\gamma}-N^{\rho} \phi^{\text {market }}\right]
$$

Due to the partial-equilibrium setup of this paper, it is natural for the social planner to consider aggregate capital and labor as exogenous. ${ }^{25}$ Note that the market structure affects the planner's problem only through the exogenous process of the fixed cost. For this problem to be well defined, we assume that $\rho>\gamma$. Under this assumption, the number of firms has two offsetting effects on the aggregate output. An increase in the number of firms increases both aggregate gross output and aggregate fixed cost.

\footnotetext{
${ }^{25}$ This problem is different from that of Dixit and Stiglitz (1977) in that the cost function is parameterized and that the utility function is not introduced. This makes it easy to consider monopolistic competition and increasing returns simultaneously.
} 
The solution of this problem gives the optimal number of firms and the optimal output:

$$
\begin{aligned}
N^{\text {planner }} & =\left(1-\frac{\gamma}{\rho}\right)^{\frac{1}{\gamma}}\left(1-\frac{\gamma}{\mu}\right)^{\frac{-\varepsilon}{\gamma}}\left(K^{\alpha} L^{1-\alpha}\right)^{1-\varepsilon} \\
Y^{\text {planner }} & =\frac{\gamma}{\rho}\left(1-\frac{\gamma}{\rho}\right)^{\left(\frac{\rho}{\gamma}-1\right)}\left(1-\frac{\gamma}{\mu}\right)^{-\varepsilon\left(\frac{\rho}{\gamma}-1\right)}\left(K^{\alpha} L^{1-\alpha}\right)^{\varepsilon \gamma+(1-\varepsilon) \rho} .
\end{aligned}
$$

By construction $Y^{\text {planner }} \geq Y^{\text {market }}$, where the equality holds when $\rho=\mu$. A larger degree of returns to variety is an incentive for the social planner to create more firms, i.e. $\frac{\partial}{\partial \rho} N^{\text {planner }}>0$.

Noting the similarity between the planner's economy and the market economy, we have the following relation:

$$
\left\{\begin{array}{l}
\mu<\rho \\
\mu=\rho \\
\mu>\rho
\end{array}\right\} \Longleftrightarrow\left\{\begin{array}{l}
N^{\text {planner }}>N^{\text {market }} \\
N^{\text {planner }}=N^{\text {market }} \\
N^{\text {planner }}<N^{\text {market }}
\end{array}\right\} \Longleftrightarrow\left\{\begin{array}{l}
y^{\text {planner }}<y^{\text {market }} \\
y^{\text {planner }}=y^{\text {market }} \\
y^{\text {planner }}>y^{\text {market }}
\end{array}\right\} .
$$

Figure 1 on page 27 compares the monopolistic-competition economy with the social planner's. The horizontal axis is the degree of market power $(\mu)$. It is easy to see that government intervention has room for welfare improvement by affecting the number of firms, unless the degree of market power is equal to the degree of returns to variety.

When the two degrees match as in the conventional aggregator specification of Eq. (5), the social planner has no room for improvement. With an endogenous number of firms $(\varepsilon=0)$, the graph of $Y^{p}$ in the first plot would be horizontal and tangent to $\mathrm{Y}^{\mathrm{m}}$ at its maximum, where the economy is located. In other words, an economy with the specification of Eq. (5) following Dixit and Stiglitz (1977) is not only the best in the class of monopolistic-competition economies but also as good as the social planner's economy. It has been argued that this optimality is due to the feature of constant elasticity of substitution. ${ }^{26}$ However, the more relevant reason consists in the specification that the degree of returns to variety is equal to the degree of market power. ${ }^{27}$ Note also that this particular optimality result relies on the partial-equilibrium setup of this paper. A general-equilibrium framework featuring endogenous aggregate inputs may break the optimality of the partial-equilibrium setup. For example, the equality between the outputs per firm does not imply the equality between the numbers of firms in Dixit and Stiglitz (1977), and government expenditure is welfare improving in Devereux, Head and Lapham (1996c).

\footnotetext{
${ }^{26}$ See Romer (1987) for an example.

${ }^{27}$ Benassy (1996) also points out that this match "is purely owing to an accidental implicit choice of" the degree of returns to variety.
} 


\section{Further research}

Based on the critical review of the literature, empirical work to identify the parameters needs to be done. Enough data both at aggregate and disaggregate levels might enable the identification of all the parameters in this paper. The issue is how to find a measure, say of the number of firms, relevant to this paper. As to the model, the specification of endogenous fixed costs needs further analysis. It is more appealing if we have a model which explains how the fixed cost changes endogenously in response to the change in exogenous variables. The literature on $R \& D$ with entry and exit can be a starting point. Another topic that deserves attention is to include materials as an input to the technology. Such extension makes the aggregation in an imperfectly competitive economy less straightforward, since it involves value added rather than gross output. Furthermore, it might change some results regarding returns to scale. $^{28}$

\footnotetext{
${ }^{28}$ See, for example, Hall (1986, 1988, 1990), Rotemberg and Woodford (1995), and Basu and Fernald (1997).
} 

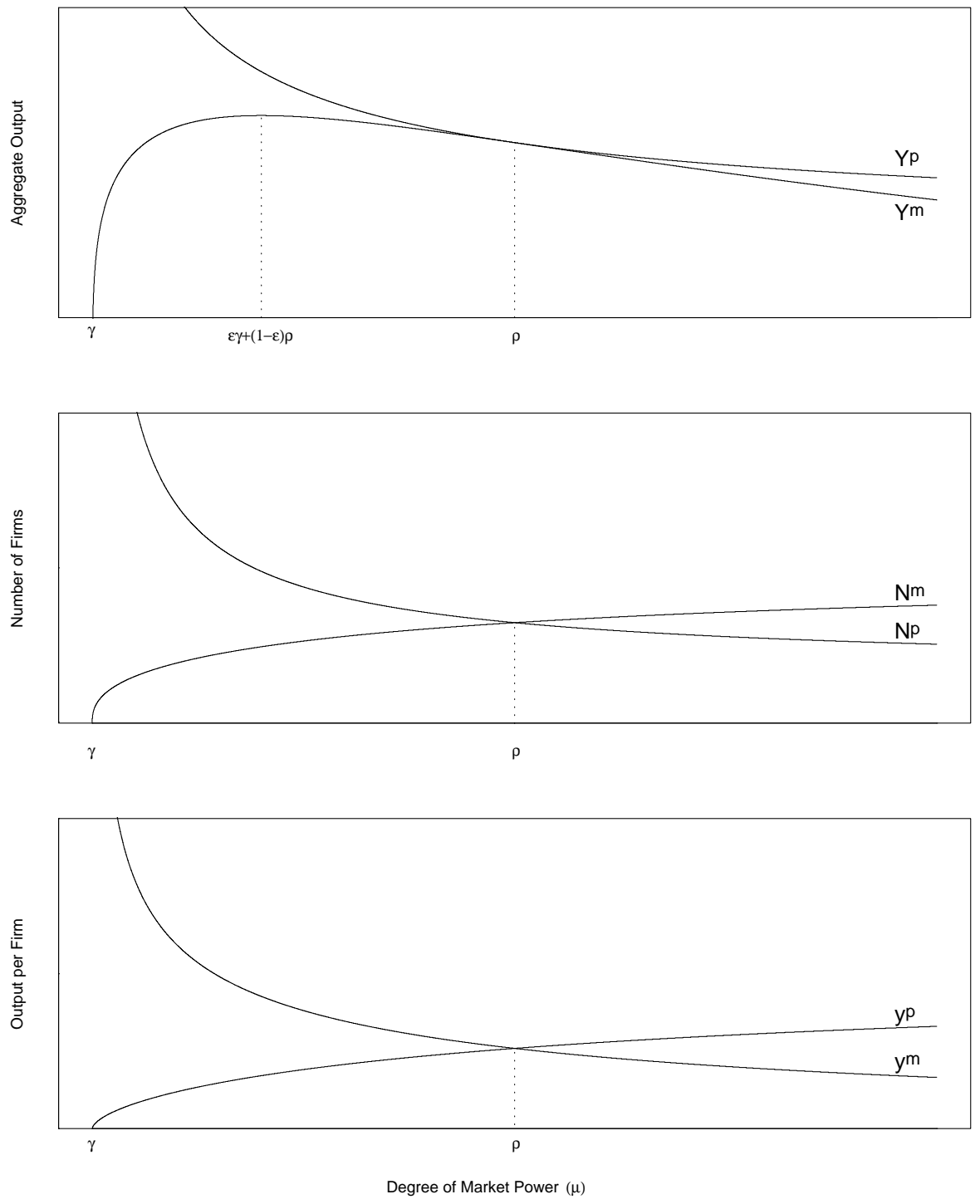

Figure 1: Comparison with a Social Planner 


\section{A External Increasing Returns}

Here we suppose that externalities come from inputs, rather than outputs. The technology of the firms without externalities, Eq. (1), is rewritten for ease of comparison: ${ }^{29}$

$$
y=\left(k^{\alpha} l^{1-\alpha}\right)^{\gamma}-\phi
$$

Input externalities have been parameterized in two different ways.

If average inputs affect the output of firms, their technology is:

$$
y=\left(k^{\alpha} l^{1-\alpha}\right)^{\gamma}\left(\bar{k}^{\alpha} \bar{l}^{1-\alpha}\right)^{\eta}-\phi,
$$

where $\bar{k}$ and $\bar{l}$ are average inputs and $\eta$ denotes the degree of externalities. Following the same procedure of the aggregation and the zero-profit condition, the degree of aggregate returns to scale in a static model is $[\tilde{\varepsilon}(\gamma+\eta)+(1-\tilde{\varepsilon}) \rho]$. Note that externalities via average inputs change the degree of diminishing marginal cost from $\gamma$ to $(\gamma+\eta)$, without any change in the degree of returns to variety. In a dynamic case, since the relative size of fixed costs depends on the internal increasing returns only, the effect of market structure is magnified by a factor of $\frac{\gamma+\eta}{\gamma}$. That is, the returns to scale in our most general specification is,

$$
\beta[\tilde{\varepsilon}(\gamma+\eta)+(1-\tilde{\varepsilon}) \rho]+(1-\beta)\left[\left(\frac{\gamma+\eta}{\gamma}\right) \mu\right] .
$$

Production externalities may come through total inputs as follows:

$$
y=\left(k^{\alpha} l^{1-\alpha}\right)^{\gamma}\left(K^{\alpha} L^{1-\alpha}\right)^{\eta}-\phi
$$

where $K$ and $L$ denote total capital and labor in the economy. Such externalities magnify not only the degree of diminishing marginal cost but also that of returns to variety by a factor of $\frac{\gamma+\eta}{\gamma}$. The degree of market power is magnified, too. The degree of returns to scale is,

$$
\left(\frac{\gamma+\eta}{\gamma}\right)[\beta(\tilde{\varepsilon} \gamma+(1-\tilde{\varepsilon}) \rho)+(1-\beta) \mu] .
$$

The above algebra shows that a model with external increasing returns and one with internal increasing returns can replicate the dynamic properties of each other, subject to the following qualification. ${ }^{30}$ The degree of returns to variety and the degree of market power should be changed appropriately. For example, if internal returns are replaced with external returns, the degree of market power in a new model should be reduced to $\left(\frac{\mu}{\gamma}\right)$, the old degree of market power divided by the degree of internal returns.

\footnotetext{
${ }^{29}$ In the Appendix, all subscripts denoting firm and time are omitted.

${ }^{30}$ This equivalence is also explained in Benhabib and Farmer (1994).
} 


\section{B Input Fixed Cost}

Suppose that the firms pay fixed costs as part of their inputs as well as their output. Then the technology of the firms is:

$$
y=\left(\left(k-k_{0}\right)^{\alpha}\left(l-l_{0}\right)^{1-\alpha}\right)^{\gamma}-\phi
$$

where $k_{0}$ and $l_{0}$ are input fixed costs. The aggregate version of the zero-profit condition is:

$$
\phi N^{\gamma}=\left[1-\frac{\gamma}{\mu}\left(\alpha \frac{K}{K-N k_{0}}+(1-\alpha) \frac{L}{L-N l_{0}}\right)\right]\left(\left(K-N k_{0}\right)^{\alpha}\left(L-N l_{0}\right)^{1-\alpha}\right)^{\gamma} .
$$

Unless there is no output fixed cost $(\phi=0)$, this condition is not analytically tractable. Assuming that there is no output fixed cost, the aggregate technology and the zero-profit condition are simplified as follows:

$$
\begin{aligned}
Y & =N^{\rho-\gamma}\left(\left(K-N k_{0}\right)^{\alpha}\left(L-N l_{0}\right)^{1-\alpha}\right)^{\gamma}, \\
\frac{\mu}{\gamma} & =\alpha \frac{K}{K-N k_{0}}+(1-\alpha) \frac{L}{L-N l_{0}} .
\end{aligned}
$$

With both input fixed costs, the zero-profit condition has a conceptual problem. Interpreted as an equation determining $N$, it produces two discrete solutions. If $k_{0}$ and $l_{0}$ are endogenous, it has a continuum of solutions. Therefore, we need to pin down either $\left(\frac{K}{K-N k_{0}}\right)$ or $\left(\frac{L}{L-N l_{0}}\right)$. With the two ratios defined as $R_{K}$ and $R_{L}$, the linearized version is:

$$
\begin{aligned}
\frac{d Y}{Y}= & (\rho-\gamma) \frac{d N}{N} \\
& +\gamma\left[\alpha\left(R_{K} \frac{d K}{K}-\left(R_{K}-1\right) \frac{d\left(N k_{0}\right)}{N k_{0}}\right)+(1-\alpha)\left(R_{L} \frac{d L}{L}-\left(R_{L}-1\right) \frac{d\left(N l_{0}\right)}{N l_{0}}\right)\right] \\
0= & \alpha R_{K}\left(R_{K}-1\right)\left[\frac{d K}{K}-\frac{d\left(N k_{0}\right)}{N k_{0}}\right]+(1-\alpha) R_{L}\left(R_{L}-1\right)\left[\frac{d L}{L}-\frac{d\left(N l_{0}\right)}{N l_{0}}\right] .
\end{aligned}
$$

If the input fixed costs are exogenous and the number of firms responds instantaneously, the linearized aggregate reduced-form production function is:

$$
\begin{aligned}
\frac{d Y}{Y}= & \lambda\left[(\rho-\gamma)+\gamma\left(\alpha+(1-\alpha)\left(R_{L}-R_{K}+1\right) \frac{R_{L}-1}{R_{K}-1}\right)\right] \frac{d K}{K} \\
& +(1-\lambda)\left[(\rho-\gamma)+\gamma\left((1-\alpha)+\alpha\left(R_{K}-R_{L}+1\right) \frac{R_{K}-1}{R_{L}-1}\right)\right] \frac{d L}{L}
\end{aligned}
$$


where $\lambda=\frac{\alpha R_{K}\left(R_{K}-1\right)}{\alpha R_{K}\left(R_{K}-1\right)+(1-\alpha) R_{L}\left(R_{L}-1\right)}$. With all the complexity of the functional form, the degree of returns to scale is simply $\rho$. However, we may assume that more unproductive inputs are necessary in a boom. If the aggregate input fixed costs are endogenous, the aggregate production function in a reduced form is:

$$
\frac{d Y}{Y}=\gamma\left(\alpha \frac{d K}{K}+(1-\alpha) \frac{d L}{L}\right) .
$$

The degree of returns to scale is $\gamma$.

In a dynamic case when the adjustments occur only at the steady state, the linearized aggregate reduced-form production function is:

$$
\frac{d Y}{Y}=\gamma\left(\alpha R_{K} \frac{d K}{K}+(1-\alpha) R_{L} \frac{d L}{L}\right) .
$$

The zero-profit condition implies that the degree of returns to scale is $\mu$. The model of Yun (1996) introduces only labor fixed cost, i.e. $k_{0}=0$, and so magnifies only labor fluctuations in output dynamics.

The bottom line of this appendix is that the model with both input fixed costs has richer dynamics in the sense that capital and labor fluctuations may be magnified to a different degree. However, this comes at a cost of one additional restriction. Three extreme cases show that the degree of returns to scale is the same as that of the model with only the output fixed cost. 


\section{Cost Minimization}

The framework of cost minimization has been used widely, for example in Hornstein (1993) and Devereux, Head and Lapham (1996a). The cost function of a firm is defined with rescaled input prices:

$$
c(y)=\min _{(k, l)} \alpha Z k+(1-\alpha) W l \text { s.t. } k^{\alpha} l^{1-\alpha}=(y+\phi)^{\frac{1}{\gamma}},
$$

where the general price level, $P$, is normalized to 1 . The first order conditions produce the conditional demands:

$$
\begin{aligned}
k & =\left(\frac{W}{Z}\right)^{1-\alpha}(y+\phi)^{\frac{1}{\gamma}}, \\
l & =\left(\frac{Z}{W}\right)^{\alpha}(y+\phi)^{\frac{1}{\gamma}} .
\end{aligned}
$$

So the cost function is:

$$
c(y)=Z^{\alpha} W^{1-\alpha}(y+\phi)^{\frac{1}{\gamma}} .
$$

Profit maximization subject to the output demand of the aggregator, Eq. (8), implies the constant markup rule:

$$
\frac{p}{\mathrm{mc}}=\mu
$$

where $\mathrm{mc}=Z^{\alpha} W^{1-\alpha} \frac{1}{\gamma}(y+\phi)^{\frac{1}{\gamma}-1}$. The marginal cost is decreasing if $\gamma>1$. However, the second-order sufficient condition is satisfied in equilibrium, since fixed cost is assumed to be positive. The maximized profit is:

$$
\pi^{*}=Z^{\alpha} W^{1-\alpha}(y+\phi)^{\frac{1}{\gamma}-1}\left[\frac{\mu}{\gamma} y-(y+\phi)\right] .
$$

Therefore, the condition of zero profits at each period results in the following relation:

$$
\phi=\left(\frac{\mu}{\gamma}-1\right) y
$$

which involves output rather than inputs as in Eqs. (4) and (11). This relation shows that output per firm is proportional to the fixed cost, whether it is exogenous or not.

Interpreting the zero-profit condition as follows:

$$
\begin{aligned}
N^{\rho} & =\left[\left(\frac{\mu}{\gamma}-1\right) Y\right]^{(1-\epsilon)}, \\
\phi & =\left[\left(\frac{\mu}{\gamma}-1\right) Y\right]^{\epsilon},
\end{aligned}
$$


we transform the conditional demands and the cost function into an aggregate version as follows:

$$
\begin{gathered}
K=\left(\frac{W}{Z}\right)^{1-\alpha} \Gamma Y^{\frac{\epsilon}{\gamma}+\frac{1-\epsilon}{\rho}} \\
L=\left(\frac{Z}{W}\right)^{\alpha} \Gamma Y^{\frac{\epsilon}{\gamma}+\frac{1-\epsilon}{\rho}} \\
C(Y ; N(Y), \phi(N))=Z^{\alpha} W^{1-\alpha} \Gamma Y^{\frac{\epsilon}{\gamma}+\frac{1-\epsilon}{\rho}},
\end{gathered}
$$

where $\Gamma=\frac{\left(\frac{\mu}{\gamma}\right)^{\frac{1}{\gamma}}}{\left(\frac{\mu}{\gamma}-1\right)^{(1-\epsilon)\left(\frac{1}{\gamma}-\frac{1}{\rho}\right)}}$. The constant markup rule is expressed as follows:

$$
\frac{p}{\mathrm{MC}}=\mu
$$

where $p=\left[\left(\frac{\mu}{\gamma}-1\right) Y\right]^{(1-\epsilon)\left(\frac{\rho-1}{\rho}\right)}$ and $\mathrm{MC}=Z^{\alpha} W^{1-\alpha} \frac{1}{\gamma} \frac{\left(\frac{\mu}{\gamma}\right)^{\frac{1-\gamma}{\gamma}}}{\left(\frac{\mu}{\gamma}-1\right)^{(1-\epsilon) \frac{1-\gamma}{\gamma}}} Y^{\epsilon \frac{1-\gamma}{\gamma}}$. MC is not the aggregate marginal cost but just a name for the aggregate counterpart of the firm's marginal cost. Note that the inverse of the markup is equal to $\frac{\partial}{\partial Y} C(Y ; N, \phi)$ evaluated at the zero-profit condition, not to $\frac{d}{d Y} C(Y ; N(Y), \phi(Y))$.

Eqs. (30)-(32) are a complete description of the economy. Solving for $Y$ as a function of $K$ and $L$, we have:

$$
Y=\left(\Gamma^{-1} K^{\alpha} L^{1-\alpha}\right)^{\left(\frac{\epsilon}{\gamma}+\frac{1-\epsilon}{\rho}\right)^{-1}}
$$

The degree of returns to scale is the weighted harmonic average of the degree of diminishing marginal cost and that of returns to variety. The input prices are:

$$
\begin{aligned}
Z & =\frac{Y}{K}, \\
W & =\frac{Y}{L} .
\end{aligned}
$$

This shows that our results on input prices in a static model are robust to the choice of the framework. 


\section{Fixed Cost Externalities}

In the static case, both the fixed cost and the number of firms are endogenous and so the degree of returns to scale is a convex combination of the degree of diminishing marginal cost and that of returns to variety. This appendix shows that the static model is equivalent to two models where the fixed cost is exogenous and only the number of firms is endogenous, i.e. $\varepsilon=0$. That is, aggregate output and the number of firms follow Eqs. (10) and (12), rewritten here for convenience.

$$
\begin{aligned}
Y & =N^{(\rho-\gamma)}\left(K^{\alpha} L^{1-\alpha}\right)^{\gamma}-N^{\rho} \phi, \\
N & =\left(\frac{\left(1-\frac{\gamma}{\mu}\right)}{\phi}\right)^{\frac{1}{\gamma}} K^{\alpha} L^{1-\alpha} .
\end{aligned}
$$

Instead of endogenous fixed costs, each model introduces an assumption about fixed cost externalities. The new parameters, $\xi$ and $v$, represent the external diseconomies such as congestion effects.

First, external diseconomies are assumed to affect the fixed cost as follows:

$$
\phi=\phi_{1} Y^{\xi}
$$

where $\xi \in[0,1]$. An increase in aggregate output would increase the fixed cost per firm, less than proportionately. Combining Eq. (33) with the above two equations, the equilibrium aggregate output is:

$$
Y=\left(\Xi K^{\alpha} L^{1-\alpha}\right)^{\left(\frac{\xi}{\gamma}+\frac{1-\xi}{\rho}\right)^{-1}}
$$

where $\Xi=\phi_{1}^{-\left(\frac{\rho-\gamma}{\rho \gamma}\right)}\left(\frac{\gamma}{\mu}\right)^{\frac{1}{\rho}}\left(1-\frac{\gamma}{\mu}\right)^{\left(\frac{\rho-\gamma}{\rho \gamma}\right)}$. The degree of returns to scale is a harmonic average of the degree of diminishing marginal cost and that of returns to variety.

Alternatively, negative externalities is assumed with respect to the number of firms as follows:

$$
\phi=\phi_{2} N^{v},
$$

where $v \in[0, \infty)$. An increase in the number of firms would increase the fixed cost per firm, possibly more than proportionately. The same algebra shows that the equilibrium output is:

$$
Y=\Upsilon\left(K^{\alpha} L^{1-\alpha}\right)^{\left[\left(\frac{v}{v+\gamma}\right) \gamma+\left(\frac{\gamma}{v+\gamma}\right) \rho\right]},
$$

where $\Upsilon=\phi_{2}^{-\left(\frac{\rho-\gamma}{v+\gamma}\right)}\left(1-\frac{\gamma}{\mu}\right)^{\left(\frac{\rho-\gamma}{v+\gamma}\right)}\left[1-\phi_{2}^{\frac{v}{v+\gamma}}\left(1-\frac{\gamma}{\mu}\right)^{\frac{\gamma}{v+\gamma}}\right]$. As the degree of externality $(v)$ grows from 0 to $\infty$, the degree of returns to scale moves from the degree of returns to variety $(\rho)$ to the degree of diminishing marginal cost $(\gamma)$. 


\section{References}

[1] Ambler, Steve and Emanuela Cardia (1996), "The Cyclical Behavior of Wages and Profits under Imperfect Competition," mimeo, University of Montreal.

[2] d'Aspremont, Claude, Rodolphe Dos Santos Ferreira, and Louis-Andre GerardVaret (1996), "On the Dixit-Stiglitz Model of Monopolistic Competition," American Economic Review, 86(3), 623-629.

[3] Basu, Susanto and John G. Fernald (1997), "Returns to Scale in U.S. Production: Estimates and Implications," forthcoming in Journal of Political Economy.

[4] Beaudry, Paul and Michael B. Devereux (1995a), "Money and the Real Exchange Rate with Sticky Prices and Increasing Returns," Carnegie-Rochester Conference Series on Public Policy, 43, 55-102.

[5] Beaudry, Paul and Michael B. Devereux (1995b), "Monopolistic Competition, Price Setting and the Effects of Real and Monetary Shocks," mimeo, University of British Columbia.

[6] Benassy, Jean-Pascal (1991), "Monopolistic Competition," in W. Hidebrand and H. Sonnenschein, eds., Handbook of Mathematical Economics, Volume IV, 1997-2045.

[7] Benassy, Jean-Pascal (1996), "Taste for Variety and Optimum Production Patterns in Monopolistic Competition," Economics Letters, 52, 41-47.

[8] Benhabib, Jess and Roger E. A. Farmer (1994), "Indeterminacy and Increasing Returns," Journal of Economic Theory, 63, 19-41.

[9] Blanchard, Olivier J. and Nobuhiro Kiyotaki (1987), "Monopolistic Competition and the Effects of Aggregate Demand," American Economic Review, 77(4), $647-666$.

[10] Chatterjee, Satyajit and Russell W. Cooper (1993), "Entry and Exit, Product Variety and the Business Cycle," NBER WP \#4562.

[11] Devereux, Michael B., Allen C. Head, and Beverly J. Lapham (1996a), "Monopolistic Competition, Increasing Returns, and the Effects of Government Spending," Journal of Money, Credit, and Banking, 28(2), 233-254. 
[12] Devereux, Michael B., Allen C. Head, and Beverly J. Lapham (1996b), "Aggregate Fluctuations with Increasing Returns to Specialization and Scale," Journal of Economic Dynamics and Control, 20, 627-656.

[13] Devereux, Michael B., Allen C. Head, and Beverly J. Lapham (1996c), "Government Spending and Welfare with Returns to Specialization," mimeo, University of British Columbia and Queen's University.

[14] Dixit, Avinash K. and Joseph Stiglitz (1975), "Monopolistic Competition and Optimum Product Diversity," University of Warwick WP \#64.

[15] Dixit, Avinash K. and Joseph Stiglitz (1977), "Monopolistic Competition and Optimum Product Diversity," American Economic Review, 67, 297-308.

[16] Feenstra, Robert C. (1994), "New Product Varieties and the Measurement of International Prices," American Economic Review, 84(1), 157-177.

[17] Hairault, Jean-Olivier and Franck Portier (1993), "Money, New-Keynesian Macroeconomics and the Business Cycle," European Economic Review, 37, 1533-1568.

[18] Hall, Robert E. (1986), "Market Structure and Macroeconomic Fluctuations," Brookings Papers on Economic Activity, 2, 285-322.

[19] Hall, Robert E. (1988), "The Relation between Price and Marginal Cost in U.S. Industry," Journal of Political Economy, 96, 921-947.

[20] Hall, Robert E. (1990), "Invariance Properties of Solow's Productivity Residual," in P. Diamond, ed., Growth, Productivity, Unemployment, Cambridge: MIT Press, 71-112.

[21] Hornstein, Andreas (1993), "Monopolistic Competition, Increasing Returns to Scale and the Importance of Productivity Shocks," Journal of Monetary Economics, 31, 299-316.

[22] Kim, Jinill (1996), "Monetary Policy in a Stochastic Equilibrium Model with Real and Nominal Rigidities," mimeo, Yale University.

[23] Matsuyama, Kiminori (1995), "Complementarities and Cumulative Processes in Models of Monopolistic Competition," Journal of Economic Literature, 33, 701-729. 
[24] Romer, Paul M. (1987), "Growth Based on Increasing Returns Due to Specialization," American Economic Review Papers and Proceedings, 77(2), 56-62.

[25] Rotemberg, Julio J. and Michael Woodford (1995), "Dynamic General Equilibrium Models with Imperfectly Competitive Product Markets," in Frontiers of Business Cycle Research, Thomas F. Cooley (ed.), Princeton University Press, Princeton, NJ.

[26] Solow, Robert M. (1957), "Technical Change and the Aggregate Production Function," Review of Economics and Statistics, 39, 312-320.

[27] Yun, Tack (1996), "Nominal Price Rigidity, Money Supply Endogeneity, and Business Cycles," Journal of Monetary Economics, 37, 345-370. 